u.s. DEPARTMENT OF | Energy Efficiency \&

ZNGRCY Renewable Energy

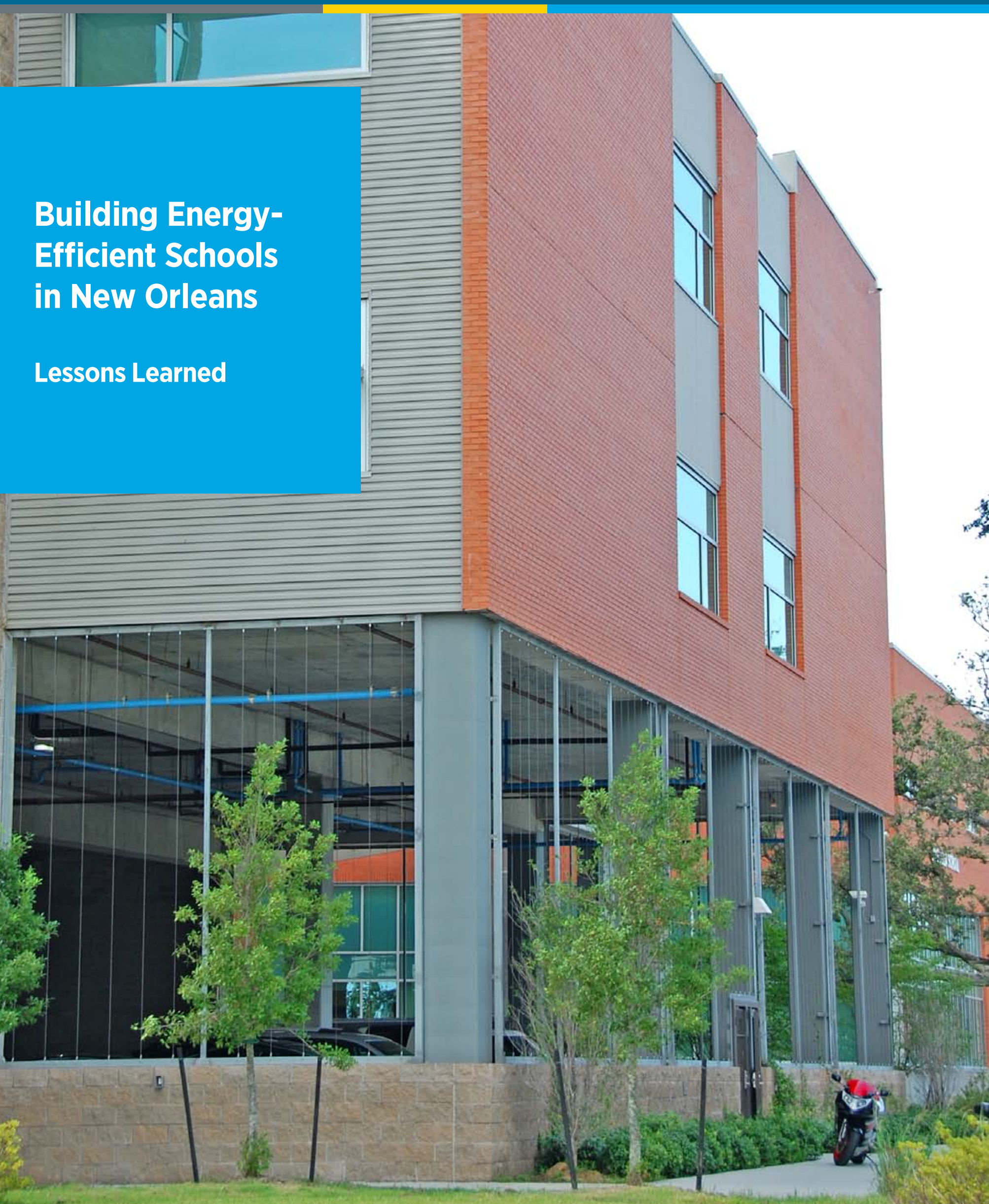



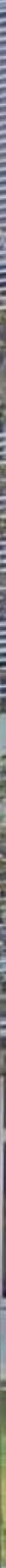

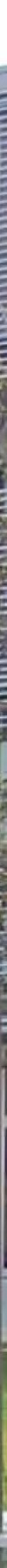




\section{The devastation of} schools in New Orleans from the hurricanes was exacerbated by many years of deferred school maintenance.

\section{- Introduction}

Hurricane Katrina was the largest natural disaster in the United States, striking the Gulf Coast on August 29, 2005, and flooding $80 \%$ of New Orleans; to make matters worse, the city was flooded again only three weeks later by the effects of Hurricane Rita. Many of the buildings, including schools, were heavily damaged. The devastation of schools in New Orleans from the hurricanes was exacerbated by many years of deferred school maintenance.

This case study presents the lessons learned from incorporating energy efficiency in the rebuilding and renovating of New Orleans K-12 schools after Hurricanes Katrina and Rita. The experiences of four new schoolsLangston Hughes Elementary School, Andrew H. Wilson Elementary School (which was 50\% new construction and $50 \%$ major renovation), L.B. Landry High School, and Lake Area High School-and one major renovation, Joseph A. Craig Elementary School-are described to help other school districts and design teams with their in-progress and future school building projects in hot-humid climates.

Before Hurricane Katrina, New Orleans had 128 public schools. As part of the recovery planning, New Orleans Public Schools underwent an assessment and planning process to determine how many schools were needed and in what locations. Following a series of public town hall meetings and a district-wide comprehensive facility assessment, a Master Plan was developed, which outlined the renovation or construction of 85 schools throughout the city, which are expected to be completed by 2017. New Orleans Public Schools expects to build or renovate approximately eight schools each year over a 10-year period to achieve 21st century schools district-wide. Reconstruction costs are estimated at nearly $\$ 2$ billion. 


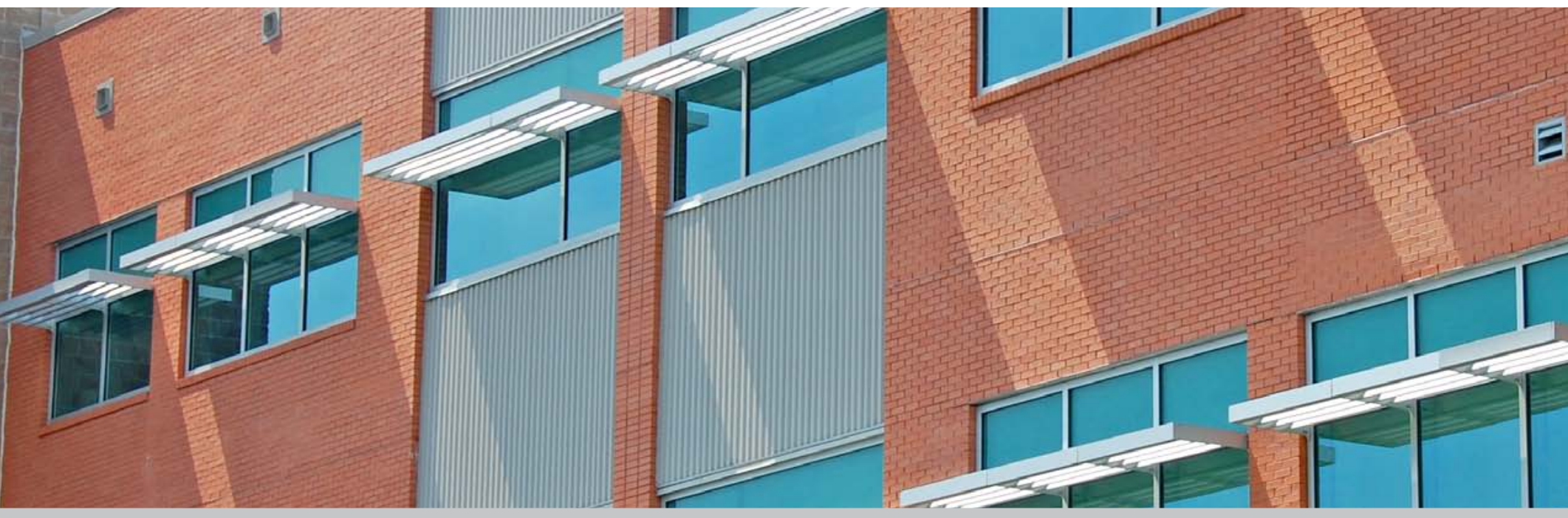

The majority of classrooms at Lake Area High School utilize daylighting thanks to the use of exterior shading and semi-transparent daylight glazing on the upper half of south-facing windows. Photo by Joe Ryan, NREL/PIX 19627

In 2007, the U.S. Department of Energy (DOE), through the National Renewable Energy Laboratory (NREL), began providing technical assistance to New Orleans' schools to improve energy efficiency and reduce school operating costs.

\section{Initial technical assistance included:}

- Energy audits of open and operating school facilities.

- Consultation on energy-efficient design strategies, energy modeling, and pre-design and design reviews for new schools. 30\% energy savings over code requirements were recommended based on strategies described in the Advanced Energy Design Guide (AEDG) for K-12 School Buildings, published by the American Society of Heating, Refrigerating and Air-Conditioning Engineers (ASHRAE).

As part of their commitment to follow the Leadership in Energy and Environmental Design (LEED) process to build sustainable school facilities, New Orleans Public Schools went one step further by striving for $31.5 \%$ energy savings for new schools to earn seven points toward LEED certification; a goal was also set for schools undergoing major renovation to achieve $25 \%$ energy savings-both above the baseline ASHRAE 90.1-2004 energy codes applicable to commercial buildings in Louisiana's hot-humid climate.

From summer 2010 through fall 2011, the operation and energy use at Langston Hughes Elementary School and Joseph A. Craig Elementary School was monitored, both at the whole-building level and at the individual system level. This effort has been key to

\section{Quick Start Schools}

In order to ensure students would have modern, permanent classrooms as quickly as possible, New Orleans Public Schools made a decision to immediately begin work to design and rebuild one school in each city council district rather than continue to spend their Federal Emergency Management Agency (FEMA) settlement money on temporary campuses. Langston Hughes Elementary School, Andrew H. Wilson Elementary School, L.B. Landry High School, and Lake Area High School were selected and built as Quick Start Schools.

*Fannie C. Williams was the 5th Quick Start School selected, but that project was delayed due to a lengthy process for accurately determining the damage to the school, which ultimately led to the decision to demolish and rebuild. 


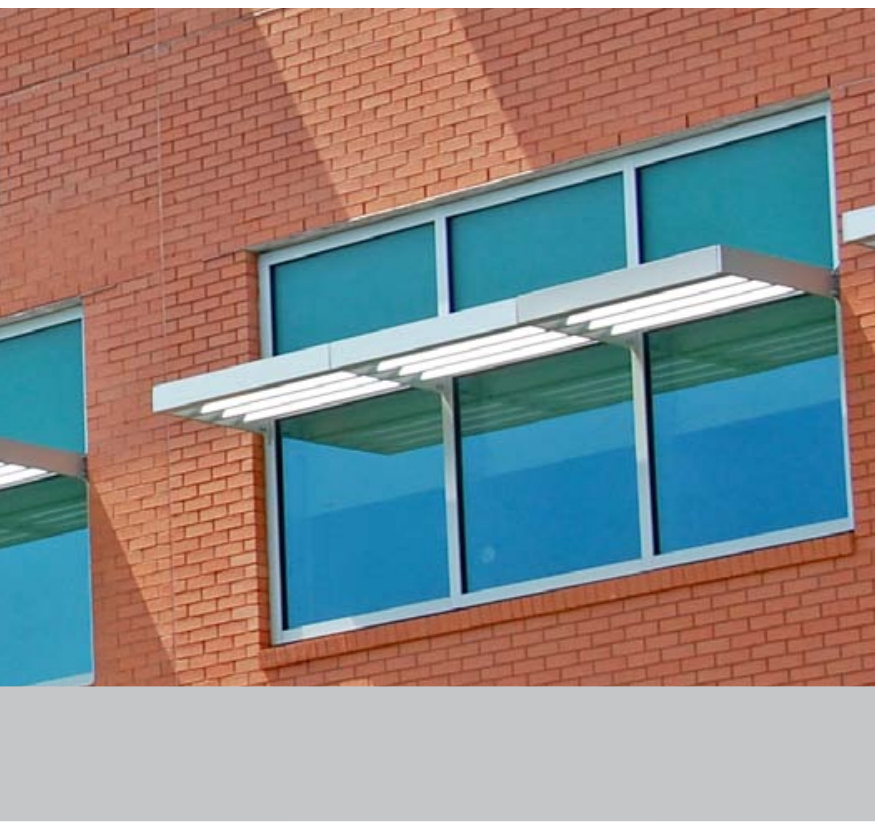

Why Act Now?

\section{Rebuilding or renovating} schools to high performance standards can have multiple positive impacts, including:

- A healthier, more productive learning environment, which has been shown to improve test scores and student attendance.

- Energy efficiency and renewable energy lessons can be incorporated into curriculum.

- Energy efficiency is cost effective, reducing the life-cycle cost of new and renovated schools. verifying the performance of energy systems, correcting any problems discovered, and capturing lessons for both design and subsequent operation of future schools to be built or renovated.

\section{Lessons Learned}

Information in this case study is based on the energy efficiency strategies for new buildings and major renovations implemented in New Orleans and the lessons learned from each project.

These lessons can help simplify the process for school districts faced with the task of building and renovating schools, helping them avoid known pitfalls, make better decisions regarding energy-efficient design strategies, and cost-effectively achieve at least 30\% energy savings over ASHRAE 90.1 (or the applicable commercial building energy code).

In New Orleans, three important lessons were identified to achieve energy-efficient buildings and cost savings after evaluating the four new schools and one renovation:

\section{Lesson 1:}

Set clear, measurable goals to achieve energy savings.

\section{Lesson 2:}

Use an integrated design approach.

\section{Lesson 3:}

Train users and evaluate system performance.

"One of the earliest lessons we learned was that the Building Automation System (BAS) must be user friendly and allow individual components and zones of the heating, ventilation, and air conditioning (HVAC) systems to be scheduled for occupied and unoccupied modes," The 'all on or all off' schedule control does not allow for systems to be in occupied mode based on actual zone demand." Thomas Arceneaux, Louisiana Recovery School District's Director of Building Commissioning and Energy Management. 


\section{What School Districts Need to Know}

When considering ways to save energy, it is helpful to gather information about energy efficiency and establish methods for achieving energy efficiency goals. Choosing team members with experience in energy-efficient design and operation of schools in your climate will help avoid hurdles that can slow less-experienced designers.

If you want to pursue LEED certification, learn about the LEED process in advance to prepare for the requirements.

Use the experiences of the New Orleans schools featured in this case study to simplify the process of building schools to achieve energy-efficient design and operation.

Before beginning any project, hire an experienced commissioning authority ( $\mathrm{CXA}$ ) to help set goals for each school and develop the Owner's Project Requirements (OPR). Set up a team dedicated to energy efficiency that includes the CxA and an energy manager or facilities manager who will participate throughout the design process and the operations and maintenance (O\&M) program.

Use cost-effective strategies for building energyefficient schools to prevent the district from running out of funding. Use an integrated design process to determine appropriate up-front design trade-offs for lower operational costs down the road to increase the district's long-term savings. Iterative energy modeling, beginning at the programming phase, identifies efficient design opportunities and trade-offs.

Allow time to train the building operations staff to use the new systems most effectively and efficiently. Even the best systems can be inefficient if your staff doesn't fully understand how to operate them properly.

\section{Use cost-effective strategies for building energy-efficient schools to prevent the district from running out of funding.}

\section{The Integrated Design Team}

To achieve maximum cost-effective energy efficiency and operability, the design team will need input from all disciplines and stakeholders throughout the design process. In addition to the architect and engineers, the team should include the:

- Building owner.

- Commissioning authority.

- Energy modeler.

- Construction manager.

- Operations and maintenance staff.

- Specialty consultants if needed.

- Representatives of the future building users.

This collaborative approach will help ensure that real-world experience is accounted for in the design and layout of the building's systems and spaces. 


\section{Project Funding}

With limited money available to rebuild and renovate schools, school districts need to stretch their available funds by spending wisely and using cost-effective strategies. Sometimes spending more up-front provides lower operational costs down the road and increases long-term savings. A design team with experience in energy efficiency working with an experienced energy modeler can help decide where to invest limited funds to have the greatest impact on energy and operational savings.

New Orleans' Public Schools received more than $\$ 1.5$ billion from FEMA to cover storm-related construction and renovationsan average of about $\$ 19$ million for each school. In addition to FEMA, the U.S. Department of Housing and Urban Development's Community Development Block Grants program provided some funding for the New Orleans schools to perform facility assessments and develop a Master Plan for addressing facility needs.

\section{The Commissioning Authority}

As the project representative for an owner, the CXA works with the owner and design team from project initiation to completion, verifying that project requirements are communicated and understood, the design satisfies the owner's expectations and goals, and that the school is constructed as designed. During different phases of a project, the CXA takes on different tasks.

\section{Pre-Design Phase}

Before design begins, the building owner (in this case the school district) hires the CxA to help develop the OPR. The CXA works with the school district during building programming to learn the number and sizes of classrooms, how the classrooms are lit, intended use of the buildings and spaces, and other important

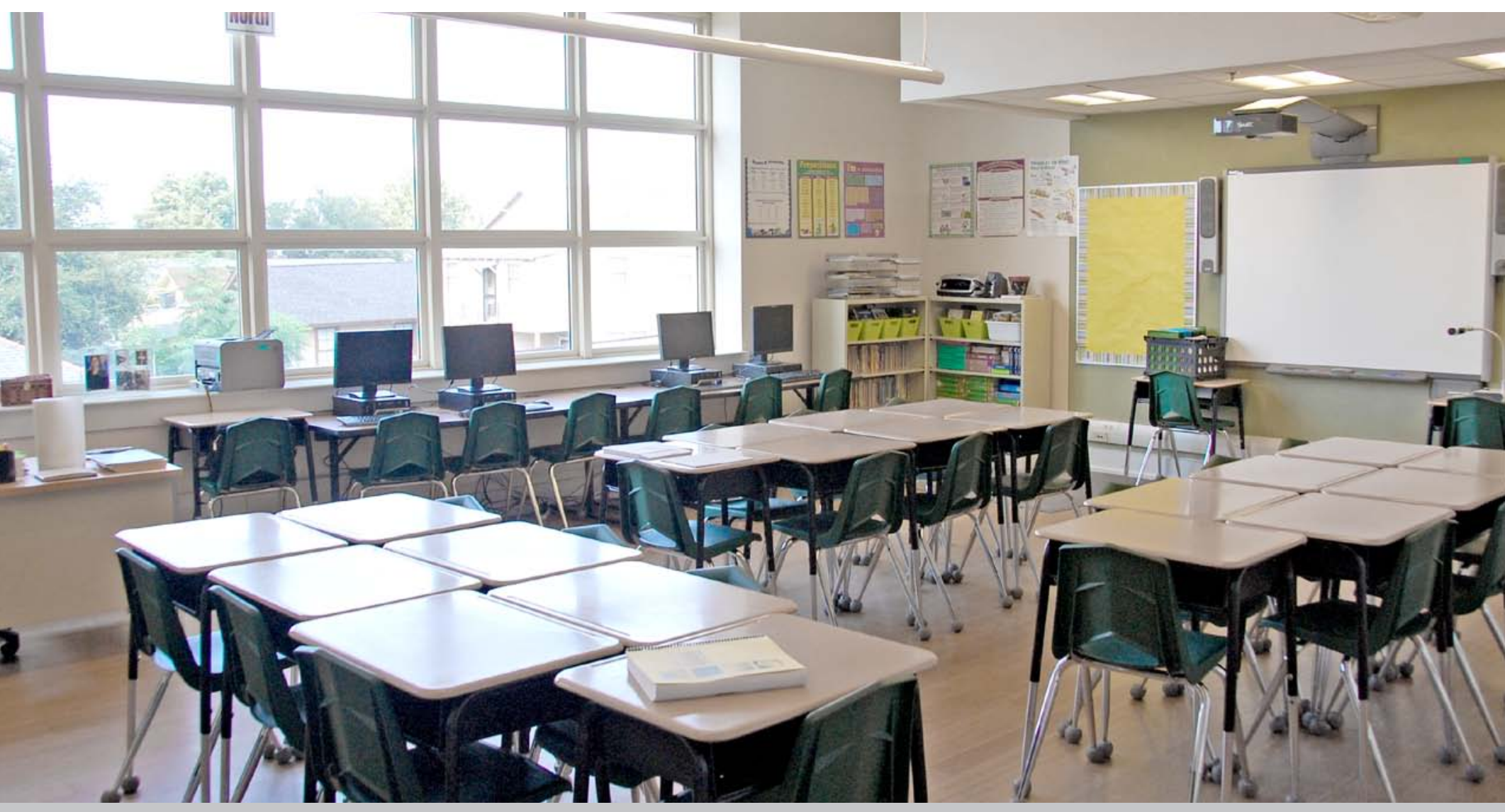

Andrew H. Wilson Elementary School's design team partnered with a daylighting leader in the United States to incorporate innovative shading devices, interior and exterior shelves, overhangs, and fabric baffles to provide daylighting to classrooms. Photo by Joe Ryan, NREL/PIX 19652 


\section{Basic Steps for Building New Schools and Renovating Schools}

Increase the chances of achieving an energy-efficient school by following these steps:

Step 1. School district officials and engineering managers should talk with experts and read current literature to learn about energy efficiency and recommended methods for achieving energy efficiency goals.

Step 2. For a renovation, perform an energy audit for a baseline of current energy use and identify opportunities for energy savings.

Step 3. Create your team and establish a set of measureable energy efficiency goals.

Step 4. Use an integrated design approach throughout the process.

Step 5. Apply strategies based on the lessons learned from building new and renovated schools in your area.

Step 6. Monitor, evaluate, adjust, and continue to monitor energy systems and operations. information for planning the new design. The OPR can also provide guidance and strategies on ways to achieve energy efficiency goals. The CXA then develops the OPR and a draft Commissioning Plan, which is shared with the responsible parties.

\section{Design Phase}

Early in the design phase, the CXA finalizes the Commissioning Plan. During the design process, the CXA provides input on specific design strategies and performs design reviews to make sure the design meets the OPR. The CXA also reviews energy model assumptions and load calculations for determining the HVAC equipment size, and design submittals to ensure equipment is sized and located properly. Then, the CXA develops specific commissioning requirements.

\section{Construction Phase}

Prior to the construction phase, the CXA provides commissioning specifications to be followed in functional testing. During construction, the CXA reviews construction submittals and building envelope construction, and witnesses and verifies functional performance testing of HVAC equipment and electrical systems for owner acceptance.

\section{Post-Construction/Acceptance Phase}

In the project's concluding periods of post-construction/acceptance, the CxA reviews operations and functionality quarterly during the first year of occupancy and then reviews performance annually (ideally) for the next 2 to 4 years. The CXA helps build the O\&M and training programs, identifies and helps resolve any issues discovered in construction or during the acceptance phase, and certifies that all energy systems meet the design intent and all issues are resolved for acceptance. The CXA may also assist in system optimization.

\section{Costs and Benefits}

Schools spend more on energy than on any other expense except personnel. Achieving energy efficiency may be the best investment a school can make and is one of the few expenses a school can reduce without sacrificing educational quality. When planning and designing new school facilities, energy efficiency does not always have to cost more than standard design practices. An integrated design process involves trade-offs in design decisions early in order to ensure the most efficient whole-building design.

For example, a high-efficiency cooling system may be more expensive than a standard-efficiency system, but combined with good insulation and windows and proper daylighting and controls strategies, the overall cooling load may be lower, allowing a smaller cooling system to 
be installed. This practice results in a small, if any, increase in overall up-front costs, while reducing operating expenses for the life of the system. Good whole-building design will have a minimal increase in costs and provide substantial benefits over the long term.

"Many of our facilities are 50 to 70 years old. Renovating or replacing these facilities allows the District to install state-of-theart material and systems, which allow for a healthier, sustainable environment for our students, faculty, and staff," - Louisiana Recovery School District

\section{- Design Basics}

When rebuilding or renovating a school, several basic energy efficiency measures, including architecture, electrical systems, energy modeling, and HVAC and mechanical design, should be addressed in the pre-design and design phases.

\section{Architecture}

Energy-efficient design begins with architecture. Architecture should make the best use of the space available and account for opportunities to minimize (or, depending on the climate, maximize) heat gain and incorporate daylighting. The building design and layout should also allow for efficient placement of mechanical systems, which will require input from engineers and maintenance personnel early in conceptual design.

\section{Site Layout and Orientation}

To give students and teachers the greatest access to natural light, classrooms should be located on wings with a long east-west axis. This allows the classrooms to use north- or south-facing glazing. As a rule for the entire building, minimize east- and west-facing glazing.

\section{Daylighting}

Daylighting reduces electricity costs by reducing the use of lights and the amount of air conditioning by providing natural light from the sun. Daylighting analysis should begin early in the design process to determine which spaces will benefit the most from daylighting and to optimize glazing size and location.

For south-facing classrooms, light shelves and exterior shading devices should be designed to minimize glare and maximize daylight penetration into the classroom. The optimum height

\section{LEED for Schools}

The LEED for Schools Rating

System is designed to guide school districts, designers, and contractors through the process of building high performance schools that have a low impact on the environment and are a healthy place for students and teachers to learn and work. LEED was developed by the U.S. Green Building Council not only as a rating system, but a process to achieve sustainable and efficient building design. LEED-certified school attributes include:

- Sustainable site selection.

- Low water use, both inside and outside.

- Low energy use through the use of energy efficiency and renewable energy.

- Reduce the use of virgin materials and transportation of materials from far away.

- Re-use existing materials and structures.

- Recycle existing materials.

- Healthy indoor environment with improved air quality, comfort, daylighting, and views. 


\section{Common}

\section{Misconceptions}

- Leaving computers on sleep mode saves energy. Actually, computers continue to consume energy in sleep mode-today's schools may have hundreds of computers in sleep mode for thousands of hours per year... turning computers "off" at the end of the day will make a bigger difference.

- More windows are better. While more windows offer more daylighting, the window area must be balanced-too much will cause glare and heating/ cooling challenges while too few will increase electric lighting loads and make spaces feel sterile, degrading the learning environment. Glazing for daylighting also requires proper placement, not just the addition of more view glass.

- For safety and security, keep outside lights on at night. Continuous nighttime lighting should be minimalusing motion sensors on indoor and outdoor lights will provide better security and save energy.

- Consider mechanical system options later in the design phase. Considering mechanical system options early and throughout the design process will save money and time in the endthese systems play an important role in energy efficiency and their design needs to be optimized and refined throughout the design process.

- Efficient systems use less energy. Efficient equipment is important, however, an energy-efficient design will only achieve its goal if an appropriate sequence of operations is implemented and regularly verified. for ceilings is at least 10', but if daylighting is provided through the roof, the height can be less than 10'. Ceilings can slope back to 8' at the interior wall if necessary to accommodate ductwork. Appropriate photosensor controls must be installed and maintained to ensure lights are turned off when natural daylight provides ample light for a space.

North-facing classrooms can benefit greatly from daylighting without the need for light shelves and shading devices since the sun will not shine directly into these classrooms.

For interior spaces, such as corridors and cafeterias, schools should consider top-lighting with tubular daylight devices. For gymnasiums, top-lighting or very high clerestory glazing should be considered.

\section{Electrical}

About half of the energy used by a school in a hot/humid climate is consumed by the lighting system and plug loads (computers, copiers, etc.). Since school is in session less than $20 \%$ of the hours in a year, keeping the lights and computers off when they are not needed presents a significant opportunity for energy savings.

\section{Additional actions for conserving electricity include:}

- Strive for overall lighting power density less than 0.9 Watt/ square foot $\left(\mathrm{ft}^{2}\right)$.

- Use photosensors (daylighting controls) to dim and turn off rows of light fixtures in rooms with access to quality daylighting. This reduces electrical consumption for both lighting and cooling.

- Use occupancy sensors (manual on/auto off) to turn off lights in frequently unoccupied spaces like conference rooms, janitor and storage closets, and offices.

- Use dual technology (ultrasonic and passive infrared) occupancy sensors to prevent false turnoffs.

- If the school receives 460 volts $(V)$ of power from the local utility, specify CSL3 high-efficiency transformers for all 110-V loads. Although these transformers have a higher initial cost, they reduce the overall utility bill by $2 \%$ to $3 \%$ annually and have a typical payback of less than five years.

\section{Energy Modeling}

Building design teams use energy modeling to estimate the effects of design choices on energy use. An energy model uses typical hourly weather data for a building's location to estimate energy use for each hour of the year. The AEDG recommends examining options for optimizing windows, insulation, and the overall building envelope as the first step in energy modeling. 


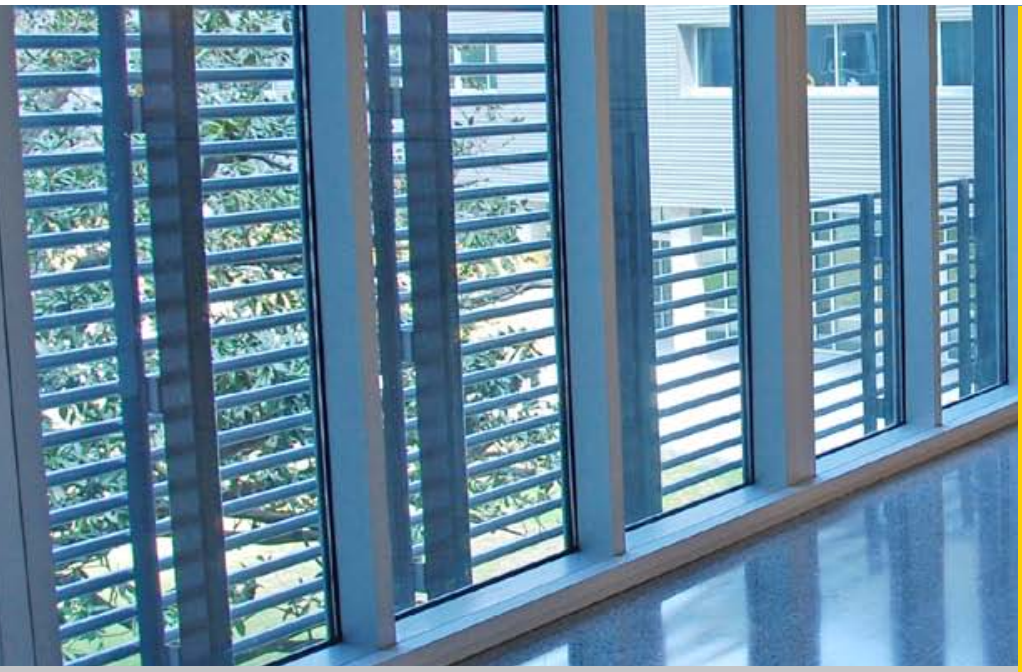

Good daylighting, as shown in the second-floor hallway at L.B. Landry High School, can have numerous benefits, including improving student performance on math and reading tests. Photo by Joe Ryan, NREL/PIX 19720

\section{Daylighting}

Good daylighting design can:

- Improve student performance.

- Create a healthier indoor environment.

- Increase attendance.

- Reduce cooling and electric lighting energy use.

A 2003 study shows that students with the best daylighting in their classrooms progressed $20 \%$ faster on math tests and $26 \%$ faster on reading tests in one year than those with minimal daylighting.

* California Energy Commission. October 2003. Windows and Classrooms: A Study of Student Performance and the Indoor Environment. P500-03-082-A-7.

\section{Items for review include:}

- Windows-sizing, placement, and specifications.

- Insulation-amount and placement in walls and roof.

After optimizing the building envelope, the design team makes decisions for the building's HVAC and lighting systems, and the energy model is updated to determine impacts of those decisions. When combined with O\&M considerations, this process results in cost-effective energy efficiency solutions.

The Quick Start School designs were intended to achieve LEED Silver certification, which required at least 37 LEED points in 2008 (the rating system has since been modified). To give the schools seven of those LEED points, energy modeling augmented the proposed building design to achieve $31.5 \%$ energy savings (over the 90.1-2004 baseline).

\section{Design improvements included:}

- Envelope insulation and window specifications.

- Outdoor air treatment.

- Chiller and boiler plant efficiency.

- Lighting power density.

- Daylighting and daylighting controls.

The LEED process is owner-driven, and requires interactive communication with the design team. To facilitate the process, a LEED template was provided to each design team showing typical credits that would be supported to meet the total points required for certification, as well as credits that were not desired and credits that should be investigated on a project specific basis.

\section{HVAC and Mechanical Design}

When renovating or building new schools, four aspects should be considered for the HVAC systems and mechanical design-outdoor air, cooling, heating, and the BAS. O\&M requirements for these systems are an important consideration, and input from O\&M staff throughout the design process should be included in mechanical system decisions.

\section{Outdoor Air}

It's most effective to use a dedicated outdoor air system (DOAS) to distribute ventilation air directly to a school's classrooms. DOAS provide much higher ventilation efficiency and reduce the amount of outdoor air needed to ventilate the building to ASHRAE 62.1 standards. Using a DOAS also makes it easier to implement a demand-controlled ventilation strategy. Substantial energy savings can be achieved by having the DOAS handle all of the building's latent (moisture) load, allowing the rest of the air handlers to reset their supply air temperature to just satisfy the sensible load of the space. This can typically be achieved with DOAS supply air dewpoints of $50^{\circ}$ to $52^{\circ} \mathrm{F}$. 
HVAC system options that work well with DOAS include four-pipe fan-coil units (FCU) and variable refrigerant flow systems. To reduce the impact of outdoor air on the building's HVAC system, schools should use energy recovery ventilators.

\section{In spaces with high and variable occupancy (like gyms, auditoriums, and cafeterias), several options are available, including:}

- Demand-controlled ventilation $\left(\mathrm{CO}_{2}\right.$ sensors or occupancy sensors).

- Variable air volume (VAV) systems.

- Occupancy sensor control of HVAC systems through the BAS (an added bonus to occupancy sensors is that they can be tied into lighting occupancy sensors to further reduce energy use).

\section{Cooling}

If using air-cooled chillers, schools should look for chillers with an integrated part load value (the measurement of chiller efficiency operating at various loads) greater than 14 . Make sure these chillers are sized to $100 \%$ of load at ASHRAE design conditions $\left(92^{\circ} \mathrm{F}\right.$ dry bulb/78 ${ }^{\circ} \mathrm{F}$ wet bulb for the New Orleans climate zone). Variable-speed chilled water pumps are best. These pumps allow variable primary flow with two-way control valves and a bypass loop.

For all space heating and cooling loads, consider a variable refrigerant flow system with energy recovery ventilation. This type of system offers energy savings similar to chilled water, but provides more precise zone control options and lower maintenance.

\section{Heating}

Schools should avoid the high operating expense of electric resistance heating. Due to electricity generation and transmission losses, electric heat is often much more expensive than heat produced with combustion appliances like natural gas, propane, and oil furnaces. The demand charges can be very high when using electric heat to warm a building on a cold morning.

\section{Suggestions to reduce or eliminate electric resistance heating include:}

- Condensing boilers. These high-efficiency boilers excel at providing moderate temperature water. An outdoor air or load reset control should be used to optimize the efficiency of the boiler. Condensing boilers can be cost-effective in well-insulated new construction buildings with an energy-efficient outdoor air strategy.

- Gas-fired furnaces. These are especially useful on roof-top units treating outdoor air in cold weather. Recirculation mode and associated ductwork should be considered for morning warm-up periods if roof-top units are combined with electric zone heaters throughout the building.

- Variable refrigerant flow. These systems efficiently provide both heating and cooling, sometimes simultaneously without the penalty of high-cost electric resistance heat.

\section{Building Automation Systems}

A central BAS with remote data access to control, monitor, record, and report performance of HVAC systems is recommended.

\section{Some control strategies for a BAS include:}

- Night/weekend temperature setback/setup (occupied/unoccupied modes).

- Optimal start/stop for HVAC systems.

- Supply air temperature reset.

- Chilled water and hot water temperature resets.

- Chiller/boiler optimization.

- Night/weekend lighting controls.

Alarm notifications to identify problems as they occur allow predictive as well as preventive maintenance.

BAS trending capability can track equipment operation and space temperatures, providing early information about movements in the wrong directions.

\section{Minimum monitoring recommendations include:}

- Out-of-bounds operating conditions.

- Static pressures to monitor condition of air filters.

- Polling variable frequency drives to ensure proper ventilation.

- Any equipment operating continuously.

- Lighting circuits to verify lights remain off when they are not needed.

A BAS should be designed to optimize the school operations for energy efficiency, but should not be so complex that it is difficult to understand and operate. The school or district facility manager should be able to monitor and operate the system effectively. 


\section{- Lesson 2: Use an Integrated Design Approach}

Using an integrated design approach from the very start of the planning process helps ensure that your school achieves the best energy performance for the least cost.

Integrated design is a collaborative, iterative process that includes a multidisciplinary design team consisting of the building owner, a CxA, an energy modeler, designers, architects, engineers, a construction manager, facility O\&M staff, other end users, and topical consultants as needed, all involved from project initiation (prior to schematic design) throughout the design process. The design team must acknowledge that design, construction, and operations all have an effect on energy efficiency, and each team member's role must be clearly defined at the start of the process. Team meetings can offer opportunities for members to share ideas, ask questions, find creative solutions, and provide feedback.

With integrated design, architects sketch concepts and then engineers and the energy modeler provide immediate input to identify problems and solutions. These specialists help the architects understand the impacts of their design decisions and help them refine the design to achieve energy goals. With information from a wide range of experts in the early project stages, it's possible to make changes that will reduce construction costs and, after occupancy, continue to save energy and money.

Acknowledging that trade-offs are part of the process, the AEDG recommends using an integrated design approach as the optimal way to achieve energy efficiency in heating, cooling, and lighting for school buildings.

"An integrated design approach has enabled the Recovery School District to achieve multiple goals including sustainability, energy efficiency and operations efficiency to build high-quality facilities while maintaining control of cost and schedules." - Louisiana Recovery School District

\section{Lesson 3: Train Users and Evaluate System Performance}

Design and installation of energy-efficient equipment is only part of the equation. Building occupants and O\&M staff need to know how to properly use, operate, and maintain the systems in newly designed school buildings. While O\&M manuals distributed by the CXA at construction meetings and school meetings serve as the primary resource for this information, hands-on training may be required for some components.

On-site operations staff should be trained to understand the day-to-day operations of each school building. This training gives them the skills to adjust system components to increase the energy-efficient operation of the school while maintaining the occupants' comfort. School operations staff and administrators should receive ongoing training, and new staff should also be provided with training when they begin. Additionally, district facility managers should solicit feedback on system performance and operability from operations staff to inform future design decisions.

A planned energy monitoring schedule is a good way to see if systems are performing as expected. In addition to tracking and comparing utility bills to energy model predictions and/or other schools of a similar design, the BAS should be programmed to store hourly trends of HVAC and lighting energy use. Evaluating performance is recommended quarterly for the first year and then at least annually after that. When problems are discovered during evaluations, the operations staff can make the required adjustments or contact the appropriate personnel to correct the problem(s).

"Training the appropriate individuals has been a challenge. Our goal is to train a core group of facilities and school staff members and allow them to train others as staffing changes at the school." - Louisiana Recovery School District. 


\section{Quarter 1 Energy Monitoring Findings at Langston Hughes Elementary School}

Elevated energy use was discovered when reviewing energy data weekly and utility bills monthly for six months.

- Projected HVAC energy use was exceeded by $50 \%$.

- Projected energy cost was exceeded by an average of $15 \%$.

\begin{tabular}{|c|c|c|c|}
\hline Causes & Q2 Solutions & Q3 Results and Recommendations & Potential Savings \\
\hline Extended hours of operation & $\begin{array}{l}\text { Reduce hours of operation for HVAC, } \\
\text { lights, and plugs }\end{array}$ & $\begin{array}{l}\text { HVAC energy use down by } 50 \% \\
\text { Minimal lighting evenings and weekends } \\
\text { Computers and copiers "sleep" after set period of inactivity } \\
\text { and turn off after school hours }\end{array}$ & $\begin{array}{l}\$ 4,000 / \text { month } \\
\sim \$ 500 / \text { month } \\
\sim ~ \$ 300 / \text { month }\end{array}$ \\
\hline $\begin{array}{l}\text { Incorrect temperature and } \\
\text { humidity setpoints }\end{array}$ & Avoid simultaneous heating and cooling & $\begin{array}{l}\text { Disable chiller plant below } 50^{\circ} \mathrm{F} \text { and disable boiler above } 80^{\circ} \mathrm{F} \\
\text { Use separate heating and cooling setpoints (heating setpoint } \\
\leq 5^{\circ} \mathrm{F} \text { lower than cooling setpoint) }\end{array}$ & $\begin{array}{l}\text { Contributes to } \$ 4,000 / \text { month } \\
\text { HVAC savings shown above }\end{array}$ \\
\hline BAS controls not optimized & Reprogram BAS for efficient operation & BAS operates more efficiently & $\begin{array}{l}\text { Contributes to } \$ 4,000 / \text { month } \\
\text { HVAC savings shown above }\end{array}$ \\
\hline
\end{tabular}

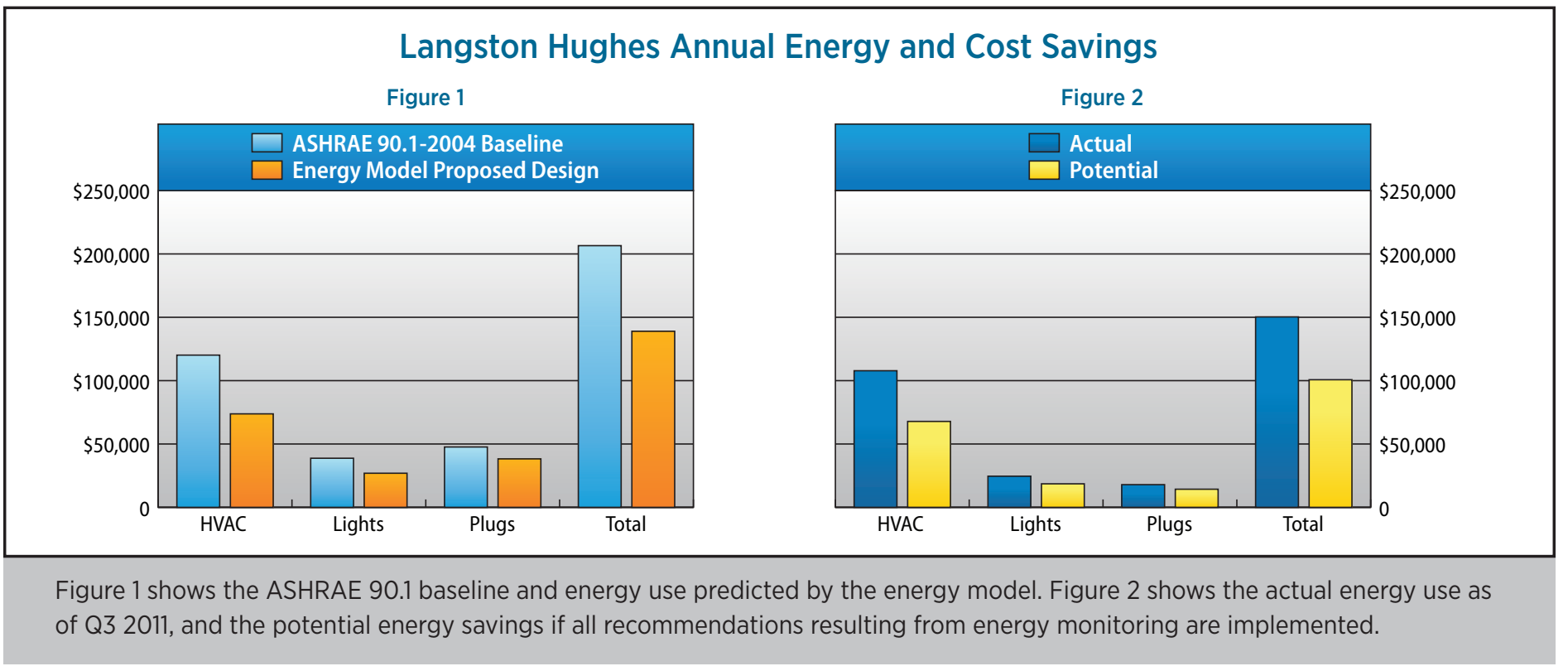

to Hughes' high utility bills (summarized in the figures above, along with solutions and potential savings). As solutions to high energy use are implemented, the energy use at Hughes moves closer to the expected performance.

\section{Lesson Learned}

Hughes was on a tight timeline for completion; however, an integrated design with the involvement of an energy modeler and daylighting consultant from the beginning would have likely resulted in a more energy-efficient design without increasing first costs or slowing the project.

\section{Energy Monitoring}

In its most basic form, energy monitoring is the process of comparing a building's actual utility bills to expectations (based on experience with other schools or an energy model). More detailed energy monitoring measures the energy used by the HVAC, lights, and plugs on a continual basis to identify trends in a school's energy use and to note findings. Energy monitoring provides information on a school's energy operations and if they are functioning as they were designed. Data that doesn't match expectations is a good indicator of a system problem to address.

The results of energy monitoring provide valuable data to help schools use less energy and save money. In addition to uncovering problems in existing systems and/or operations issues, the results provide important lessons learned for future designs of new and renovated schools. 


\section{- Joseph A. Craig Elementary School}

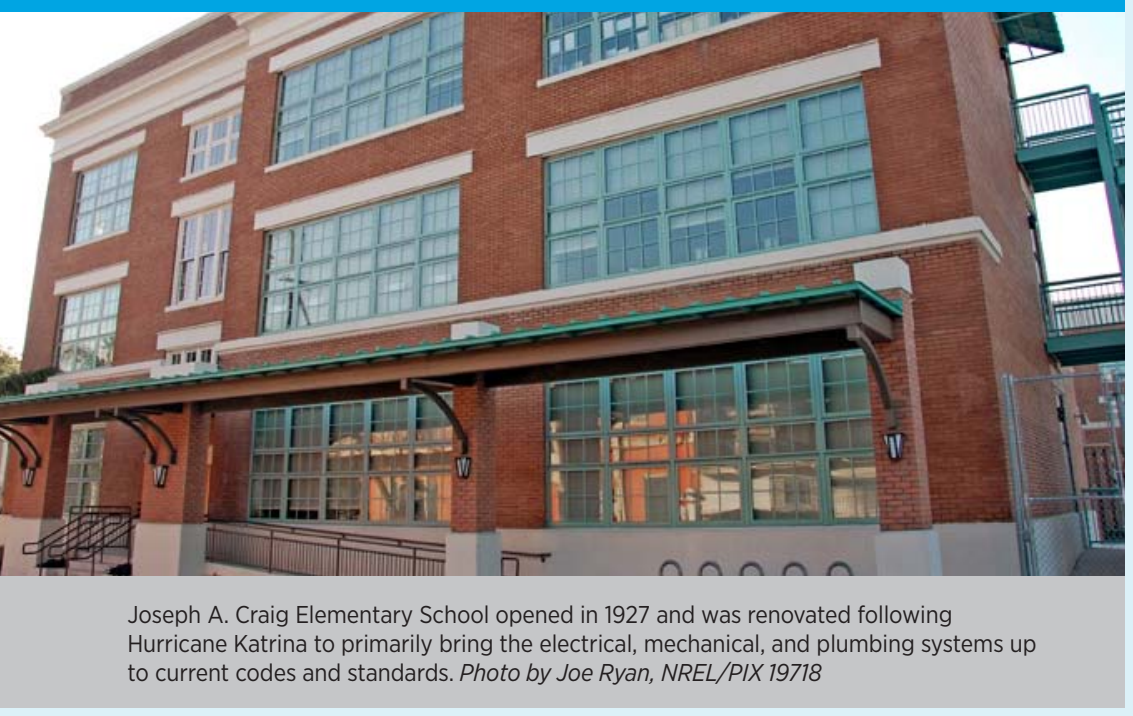

Joseph A. Craig Elementary School (Craig), located in the historic Treme neighborhood, opened in 1927 as the first new school in New Orleans built for African American children. In 2007, an environmental assessment identified a leaking roof and extensive mold. Since Craig was not a Quick Start School, its renovation was put on a fast track and planners didn't include any energy efficiency goals in their renovation plans.

However, Craig was a school in the Solar Schools Initiative (funded by Entergy, the Entergy Charitable Foundation, and Nike) and had a 25 kilowatt (kW) photovoltaic (PV) system installed. The Craig renovation included a small addition for the cafeteria and kitchen, but primarily made repairs and brought the electrical, mechanical, and plumbing systems up to current codes and standards.

\section{HVAC Design and Fan-Coil Unit}

Although the design of the Craig renovation didn't include any specific energy goals, the conservative and simple design of the school's HVAC system was a good choice for New Orleans' hot-humid climate.

To keep the classroom temperature comfortable, Craig uses energyefficient FCUs, which provide individual temperature control of each classroom and other spaces. The four-pipe FCUs in each classroom add the right amount of heating or cooling to keep the classroom at comfortable conditions, minimizing the potential for simultaneous heating and cooling in a given space.

In a hot-humid climate like New Orleans, conditioning the outdoor air necessary to bring into the building represents a substantial load on the HVAC system (typically about 1/3 of the building's
HVAC load). At Craig, outdoor air is conditioned by a DOAS and ducted to the classrooms and other spaces in the building. In colder weather, the high-efficiency condensing boilers send hot water to the DOAS units to pre-heat the outdoor air to space neutral conditions $\left(65^{\circ} \mathrm{F}, 50 \%\right.$ relative humidity). In warmhumid weather, the DOAS units use direct expansion cooling and hot-gas reheat to again supply air to the school at space neutral conditions.

Unfortunately, the DOAS units at Craig are constant volume, meaning they have two settings: on and off. This makes it difficult to implement the energy saving demand-controlled ventilation strategy, varying the amount of outdoor air introduced to the building relative to the number of occupants. With constant volume outdoor air units, it's important to operate them only when the school is substantially occupied.

\section{Energy Monitoring Findings}

Although Craig was renovated prior to the district setting energy efficiency goals, the district recognized the importance of validating energy performance in a renovated school. Through this effort, it was discovered that Craig's HVAC system wasn't shut off at the end of the day-it was on 24/7. Energy monitoring also indicated various electric loads operating 24/7. A walk-through of the building identified electric, freeze-protection heaters were improperly set and operating at warm temperatures, as well as exhaust fans operating continuously. These issues highlight how easily automated systems can be programmed improperly without the building occupants' knowledge. Because of the energy monitoring effort, simple solutions were identified to address the issues and reduce energy consumption at Craig.

\section{Lesson Learned}

Craig has a relatively straightforward HVAC system; however, seemingly benign changes to the BAS programming can have a dramatic, negative effect on the school's operation. Technology can provide a convenient means of operating sophisticated systems in modern buildings; however, automation can create unnoticed issues if sufficient training and monitoring are not provided. Training operations staff early and often on complex energy systems will ensure appropriate system use and energy savings. 


\section{L.B. Landry High School}

$+1$

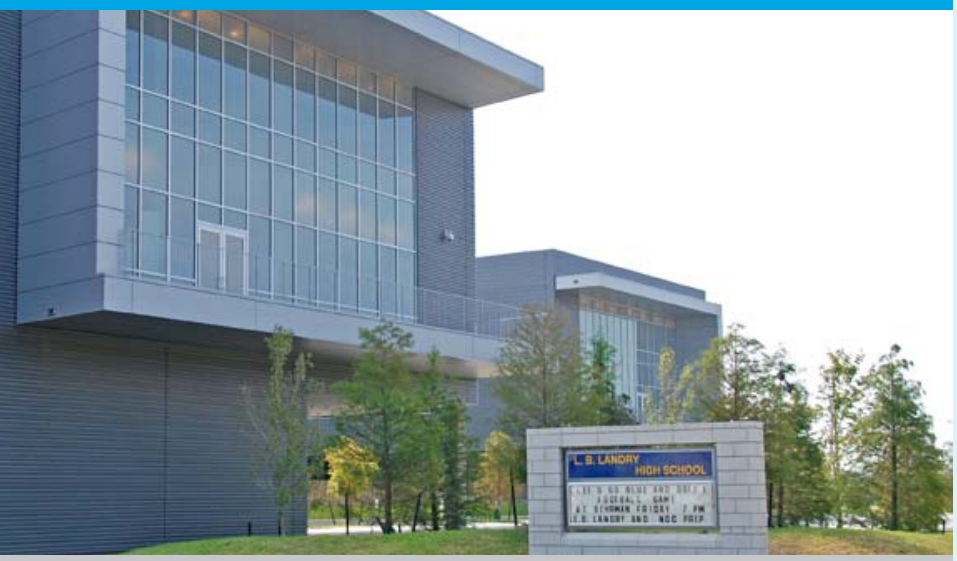

At approximately $236,000 \mathrm{ft}^{2}$, L.B. Landry High School is one of the largest new schools in New Orleans, providing a new performance gym, practice gym, and band and choir rooms for its students. Photo by Joe Ryan, NREL/PIX 19730

L.B. Landry High School (Landry) is one of two new high schools built with the initial funding from the FEMA settlement. Landry is a large school, with about $236,000 \mathrm{ft}^{2}$ of conditioned space. The new building has an auditorium, two gymnasiums, and a community health clinic and replaces a school facility that suffered more from years of neglect than the winds of Katrina. Landry uses a modern design with a conservative HVAC system and good daylighting to achieve its energy efficiency goals.

\section{Mechanical Design}

Since Landry is larger than $150,000 \mathrm{ft}^{2}$, the baseline cooling system according to LEED energy modeling requirements was a water-cooled chiller, but the engineers had chosen a less-efficient air-cooled chiller for the HVAC design. This decision made their goal of achieving $31.5 \%$ energy cost savings over the ASHRAE 90.1-04 baseline more difficult. However, by improving the building envelope and eliminating the complexities of water-cooled chillers, the designers were able to approach their goal by achieving $27 \%$ energy cost savings. The air-cooled chiller system has also been easier to maintain, resulting in more predictable and sustainable levels of energy consumption.
"Installation of high-efficiency HVAC systems does not guarantee energy savings. Systems must be integrated in a manner that allows for efficient operations."
- Louisiana Recovery School District.

\section{Daylighting and Acoustics}

Landry's performance gym, practice gym, band room, and choir room use tubular daylight devices and the 3rd floor corridors use north-facing clerestory windows to provide effective daylighting. Most of Landry's classrooms have sufficient glazing and overhangs that, when combined with the photo/ occupancy sensors and dimmable ballasts, are able to reduce the amount of electric lighting in the spaces. The north-facing windows are flush with the exterior building skin while the south-facing windows are recessed into the building skin, reducing glare and solar gains in the warmer months.

During the design phase for Landry, engineers were challenged with long duct runs and limited space for the ductwork. As a result, keeping the air noise out of the classrooms was difficult and required bringing in an acoustics expert to help solve the problem. Sound attenuation was added to the design to keep the noise out of the classroom but also necessitated larger blower motors to move the air throughout the building. These complexities increased the initial and operating costs of the HVAC system and could have been avoided if the acoustics expert had been brought in during the design phase.

\section{Lesson Learned}

By not using a true integrated design approach, the Landry design team encountered challenges. If the team had included engineers, energy modelers, and acoustics experts in the early design stages, some of the hurdles encountered later could have been avoided. Additionally, the design team did not initially receive clearly stated goals (energy savings, LEED certification, etc.) from the district because of the tight turnaround time. Establishing clear goals early in the process may have also helped to avoid some of the hurdles the team encountered later.

Although a chiller system with a higher efficiency rating could have been selected for Landry, the simpler air-cooled system has produced consistent performance and energy efficiency due to its ease of O\&M. This is an especially important consideration for managing future O\&M and energy costs. 

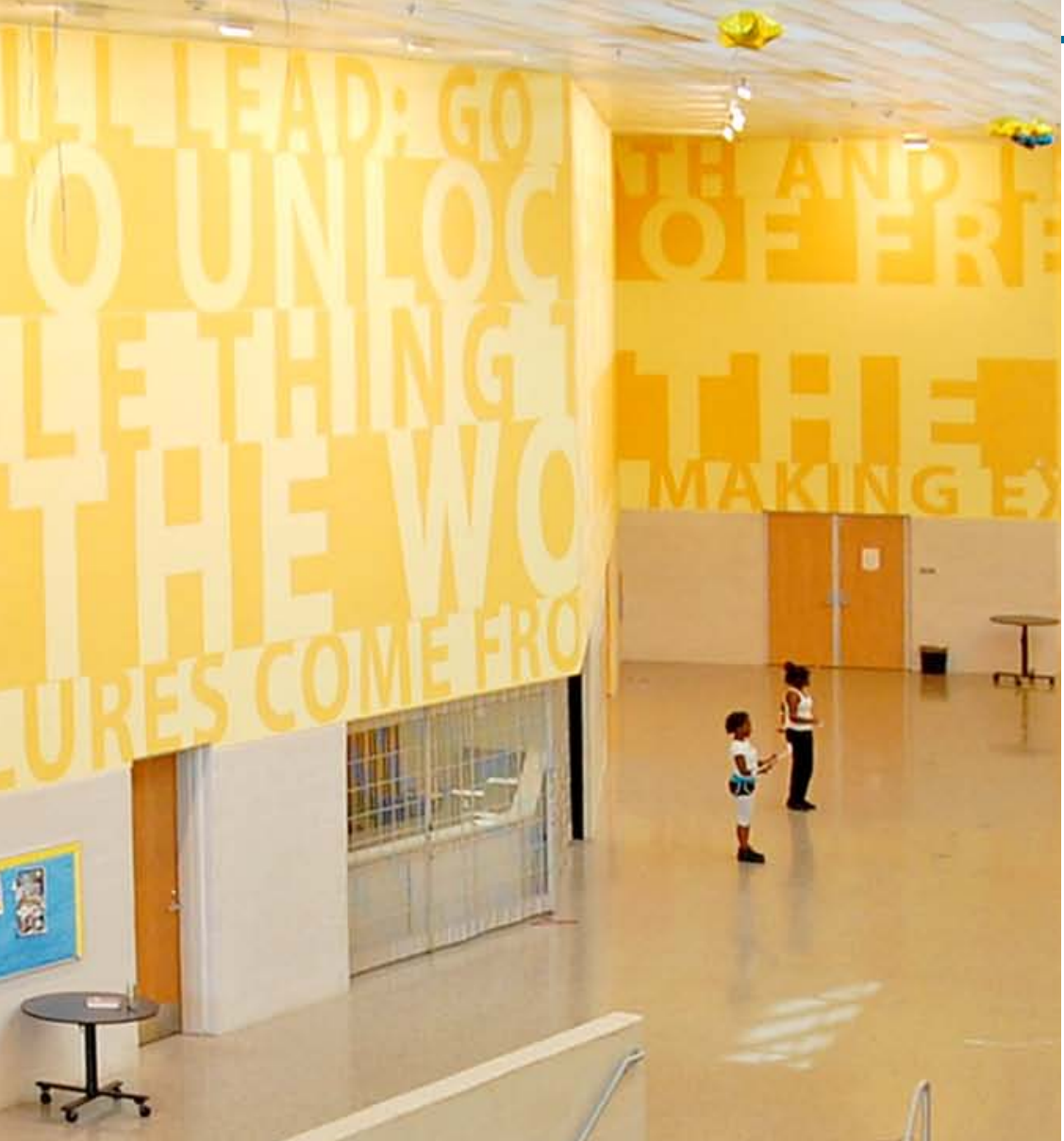

\section{- Progress and Challenges Yet to Come}

New Orleans Public Schools are showing progress in moving toward achieving their energy savings goals for new schools and renovated schools, but many challenges remain. To address these challenges, the district has established new goals.

The School Facilities Master Plan not only lays out a roadmap for when and where the district will focus its rebuilding efforts, but it also provides specifications for how the schools will be built. As part of the biennial review process, technical committees made up of contractors, designers, and district personnel recently revised the building specifications. These revisions were based on experiences with Quick Start Schools and aimed to improve the delivered product through simpler and more standardized designs.

\section{The major HVAC components specified by these revisions will be:}

- High efficiency air-cooled chillers.

- Condensing boilers.

- Four pipe FCUs in the classrooms.

- Dedicated outdoor air systems.

Additionally, the energy savings goal was revised to reflect changes to LEED and ASHRAE Standard 90.1. The new goal is $28 \%$ energy cost savings and an Energy Use Intensity of $35 \mathrm{kBtu} / \mathrm{ft}^{2} /$ year. Although this is lower than the original $31.5 \%$ target, it is a small improvement in energy efficiency because of the upgrades to the ASHRAE 90.1-2007 baseline (versus 90.1-2004).

\section{As a result of community input, other recent changes} to the master plan include:

- Reducing the projected number of schools in the city from 85 to 82 .

- Increasing available funds through the use of tax credits.

- Spreading available funds more widely among the schools by redesigning some projects, ensuring all schools in the city will be improved with currently available funding. 


\section{Quick Start Schools}

The process to design and build the Quick Start Schools provided valuable lessons learned to apply to current and new projects. The designs are good, but the schools weren't initially achieving energy efficiency expectation largely due to an ineffective sequence of operations. The challenge for each of the Quick Start Schools was to develop and implement an energy-efficient sequence of operations for all of their energy systems, and to ensure that systems continue to be properly operated and maintained.

\section{Existing Schools}

With New Orleans Public Schools' focus and extensive work on new schools and major renovations, resources to bring existing schools into an energy-efficient state of operation are limited. Some existing schools are even scheduled for demolition in a few years. Limited resources and prospects of demolition do not encourage school districts to put time and money into existing schools to reduce their energy costs. However, energy audits at these schools performed by DOE/NREL can be used to implement low-/no-cost strategies to achieve near-term, cost effective savings.

\section{- Conclusion / Summary}

The devastation caused by Hurricane Katrina, coupled with the subsequent FEMA settlement money, provided the New Orleans School District with a once-in-a-lifetime opportunity to reorganize and rebuild its ailing school facilities. The district drew on the expertise of many experts to create the School Facilities Master Plan and to develop the 10-year roadmap for rebuilding the city's schools. On a parallel path, the district built four Quick Start Schools in an effort to invest FEMA funds in permanent facilities instead of additional temporary campuses. The Quick Start Schools had the additional impact of developing the school system's procurement and school building expertise as well as gaining experience in producing schools that can achieve $30 \%$ energy savings.

\section{DOE/NREL helped schools in New Orleans with their rebuilding efforts by providing assistance with:}

- Master Plan performance specifications.

- Quick Start School design reviews.

- Quick Start School energy modeling.

- Energy monitoring of Langston Hughes and Joseph Craig elementary schools.

- Participation in the Master Plan revision process.

- Energy audits of existing and operating school facilities.

As of fall 2011, the district had completed seven major school construction projects, has 10 projects under construction, and has an additional nine projects in the design/procurement pipeline. Over the next six years, the district plans to build 17 new schools and complete major/minor renovations on an additional 39 schools, resulting in 82 schools ready for the 21st century.

As a result of the district's openness to outside expertise in revising and refining the Master Plan and lessons learned from school energy performance monitoring, these construction projects will continue to improve and achieve cost-effective energy savings. New Orleans Public Schools have shown that using an integrated design process, including all necessary team members from the first day and following up to ensure buildings perform as designed, can result in a cost-effective approach to energy-efficient schools. 


\section{Building Energy- Efficient Schools in New Orleans}

\author{
Lessons Learned
}

B. Landry High School.

Photo by Joe Ryan, NREL/PIX 16673

\section{Additional Resources}

These additional resources provide information on energy-efficient schools.

\author{
ASHRAE Advanced Energy Design Guides \\ www.ashrae.org/technology/page/938
}

U.S. Green Building Council LEED Rating System www.usgbc.org/DisplayPage.aspx?Category/D=19

Collaborative for High Performance Schools www.chps.net/dev/Drupal/node

DOE Building Energy Software Tools Directory http://appsl.eere.energy.gov/buildings/tools_directory

RebuildingNolaSchools

http://rebuildingnolaschools.wordpress.com

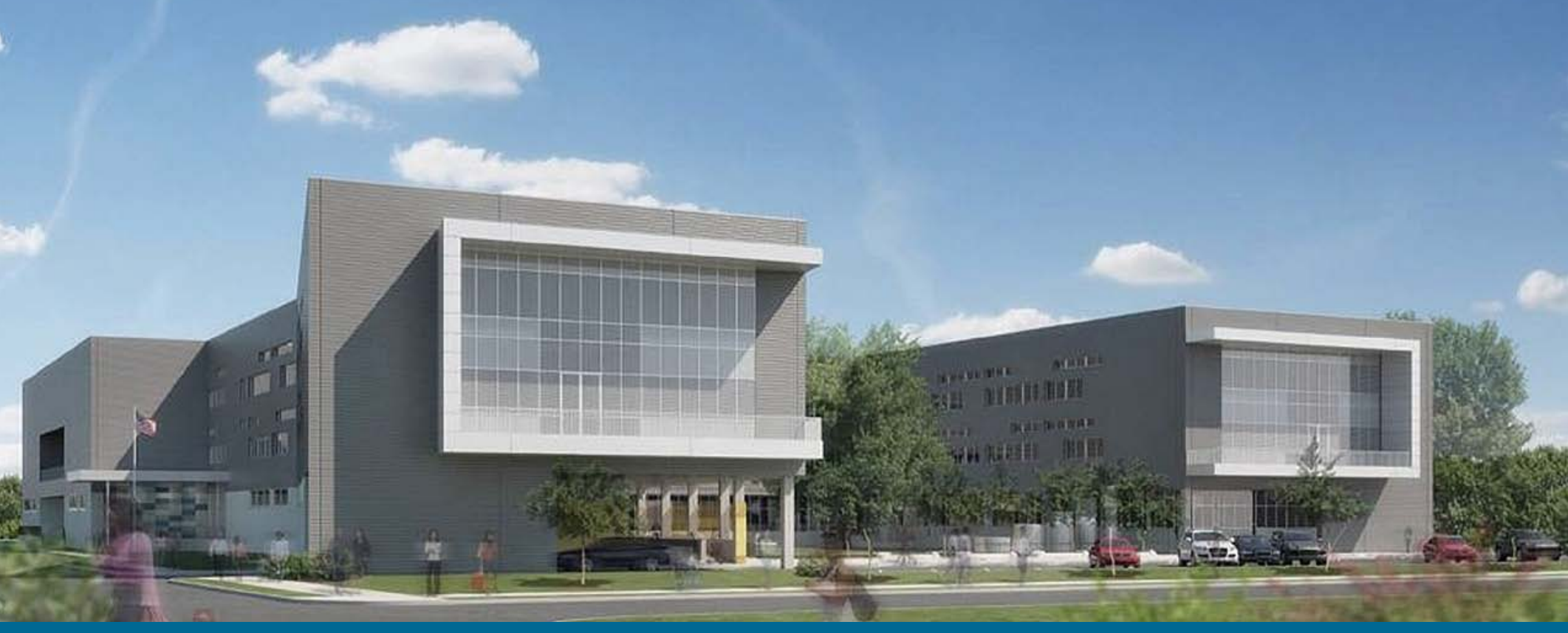

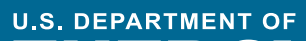

ENARQY

Energy Efficiency \&

Renewable Energy
DOE/GO-102011-3290 • December 2011

Printed with a renewable-source ink on paper containing at least $50 \%$ wastepaper, including $10 \%$ post consumer waste.
Prepared by the National Renewable Energy Laboratory (NREL), a national laboratory of the U.S. Department of Energy, Office of Energy Efficiency and Renewable Energy; NREL is operated by the Alliance for Sustainable Energy, LLC. 